\title{
Child Schooling and Child Work in the Presence of a Partial Education Subsidy ๘ $\odot$
}

\author{
Jacobus de Hoop \\ Jed Friedman \\ Eeshani Kandpal \\ Furio C. Rosati
}

\begin{abstract}
Could a partial subsidy for child education increase child labor? Using data from the randomized evaluation of a conditional cash transfer program $(C C T)$ in the Philippines, we find that children who were neither in school nor work in the absence of the program not only increased school participation but also increased work for pay. We show suggestive evidence that because the cash transfer only provided a partial schooling subsidy children worked to cover the shortfall in schooling fees. Our findings contribute to the increasing evidence that the design of CCTs, in this case transfer size, matters considerably in terms of achieving program goals.
\end{abstract}

\footnotetext{
Jacobus de Hoop is a social policy specialist at the UNICEF Office of Research-Innocenti in Florence. Jed Friedman is a senior economist in the Development Research Group of the World Bank in Washington, DC. Eeshani Kandpal is an economist in the Development Research Group of the World Bank in Washington, DC. Furio C. Rosati is a professor of economics at the University of Rome "Tor Vergata." The authors thank Pablo Acosta, Jorge Avalos, Gabriel Demombynes, Eric Edmonds, Francisco Ferreira, Deon Filmer, Yusuke Kuwayama, Berk Özler, Aleksandra Posarac, two anonymous referees, and participants in the 2015 EUDN and 2016 PopPov conferences for insightful comments and suggestions. The findings, interpretations, and conclusions expressed in this paper are entirely those of the authors. They do not necessarily represent the views of the International Bank for Reconstruction and Development/World Bank and its affiliated organizations, or those of the Executive Directors of the World Bank or the governments they represent. The views expressed here should also not be attributed to the ILO or UNICEF, or any of these agencies' member countries. The data used in this article can be obtained beginning six months after publication through three years hence from Eeshani Kandpal (ekandpal@worldbank.org).

[Submitted March 2017; accepted October 2017]; doi: 10.3368/jhr.54.2.0317.8627R1

JEL Classification: C93, I21, J22, and O22

ISSN 0022-166X E-ISSN 1548-8004 (C 2019 by the Board of Regents of the University of Wisconsin System $\checkmark$ Supplementary materials are freely available online at: http://uwpress.wisc.edu/journals/journals/ jhr-supplementary.html

ఠ This open access article is distributed under the terms of the CC-BY-NC-ND license (http:// creativecommons.org/licenses/by-nc-nd/3.0) and is freely available online at: http://jhr.uwpress.org.
}

THE JOURNAL OF HUMAN RESOURCES • $54 \cdot 2$ 


\section{Introduction}

An extensive literature consistently finds that conditional cash transfer (CCT) programs increase children's school participation (Baird et al. 2014; Fiszbein and Schady 2009; Saavedra and Garcia 2012), usually while decreasing their participation in work (de Hoop and Rosati 2014; Edmonds 2008; Edmonds and Schady 2012; Fiszbein and Schady 2009). In this paper, we present a counterexample from the experimental pilot of a conditional cash transfer program in the Philippines showing that cash transfers can, under certain conditions, increase both school enrollment and participation in paid work.

The program, Pantawid Pamilya Pilipino Program (or simply Pantawid), supports poor households (those with income less than US $\$ 2.15$ per capita per day) by providing two transfers, one conditioned on child health-related behavior and the other on schooling. ${ }^{1}$ The randomized evaluation of Pantawid (World Bank 2013) demonstrated that the program broadly achieved its primary objectives by increasing school participation of eligible children (those aged 6-14 from pre-identified poor households) by almost five percentage points and improving the health and nutrition of eligible 0-14 year olds (World Bank 2013; Kandpal et al. 2016). ${ }^{2}$ Using data from the Pantawid impact evaluation, we find that the increase in school participation was accompanied by a concomitant increase in children's participation in paid work outside the home. This increase is on the order of five percentage points, relative to a control mean of 12 percentage points in the rate of child work for pay. In particular, the program appears to have encouraged children who would otherwise be neither in school nor in work to attend school and to start working.

We consider and rule out a range of possible explanations for the increase in child labor, including investment of the transfers in household productive activities and changes in adult productive engagement, both of which can increase household demand for child labor, as well as improvements in child health, which could affect the supply of child labor. Instead, we present evidence suggesting that schooling and work for pay were complements in the face of Pantawid's partial schooling subsidy. During the evaluation period, education transfers did not fully cover the cost of education-hence, the school attendance of compliers, that is, those who started attending school in response to the program, represented a net cost to the household. The maximum annual education transfer per child was approximately US $\$ 70$, although the households in our sample received only about US\$55. Estimated primary schooling cost was US\$86 in treated areas, indicating an average shortfall of US $\$ 31$ per enrolled child; the shortfall for compliers may have been even greater. We show that the earnings of working children make up for a large portion of this shortfall. ${ }^{3}$

1. The program has been in place since 2008 and now covers more than 4.5 million poor households.

2. Children younger than age five in treated areas had higher height-for-age $z$ scores, were less likely to be severely stunted, and were more likely to eat protein-rich foods and use health services. Older children (aged 614) were more likely to be offered deworming medication.

3. The compensatory behavior we document is particularly likely to occur in ultra-poor populations and when the price of school participation exceeds the value of the subsidy by a substantive margin. A later evaluation identifying the local effect of Pantawid on the wealthiest beneficiaries (exploiting the poverty means test based on which the program is allocated) did not document a similar impact on child work (World Bank 2013). 
While we do not estimate the total welfare impact of the increase in children's school attendance and work, which would require knowledge of the full long-run benefits and costs of both school attainment and child work, this paper contributes to our understanding of the relationship between schooling and work for pay and argues for the adoption of a broader framework when assessing the cost effectiveness of possible transfer schemes. When discussing program design, the literature typically compares the size of the transfer with household income. However, our findings suggest that the cost of the behavior on which the program is conditioned (in our case school participation) is also a germane metric. A transfer too large may be wasteful if full compliance can be achieved with a smaller transfer amount (or if most transfers are inframarginal). A transfer too small may not sufficiently compensate potential compliers to modify behavior, even if the presence of positive externalities is an acknowledged motivation for the subsidy. Alternatively, a transfer that does not fully compensate for the cost of adopting the compliant behavior can result in unanticipated consequences as beneficiary households seek to supplement the partial subsidy through a labor response or an asset drawdown. ${ }^{4,5}$ While such compensatory behavior need not arise in all contexts, such as in wealthier populations, the identification of such behavior is relevant because cash transfer programs are widely implemented, including in settings with markedly lower primary school attendance rates and higher rates of idle children. The phenomenon we document could equally occur in programs encouraging secondary school participation - an issue of increasing policy concern — or when providing partial subsidies subject to other behavioral requirements. We thus interpret our findings as an example of an issue of broader concern. Our results also raise questions about the efficiency of spending in such programs since most CCTs with primary school conditions are targeting populations already at very high enrollment levels.

Finally, by documenting compensatory behavior, this paper also contributes to our understanding of the often-significant unintended consequences of CCTs, both beneficial and detrimental. While a comprehensive discussion of this literature is beyond the scope of this paper, a few germane examples include the Contreras and Maitra (2013) finding that the Colombian CCT significantly improved health outcomes among nontargeted adults in treated households. Ferreira et al. (2009) and Barrera-Osorio et al. (2011), examining a Cambodian scholarship program and the Colombian CCT, respectively, show that child-specific cash transfers may generate negative displacement effects on the schooling of ineligible siblings. Finally, several studies have also found that peer effects can increase school enrollment of nontargeted populations, at least in the case of Mexico's PROGRESA/Oportunidades/Prospera CCT (Bobba and Gignoux 2014; Bobonis and Finan 2009; Lalive and Cattaneo 2009).

4. From an efficiency standpoint, it may be optimal to induce a small amount of child labor, particularly since evidence suggests only a partial negative tradeoff between child labor and human capital formation (Akabayashi and Psacharopoulos 1999).

5. A few studies have examined how labor supply, including by children, can help households respond to income shocks. Jacoby and Skoufias (1997) find that households smooth seasonal fluctuations in consumption by drawing upon their children's labor, and that such fluctuations have negligible average effects on human capital. Banerjee, Karlan, and Zinman (2015) show that a relatively small loan to acquire an expensive durable good may lead to complex adjustments in household consumption and labor supply. Various other studies find that microcredit programs may increase children's participation in productive activities (Augsburg et al. 2016; Nelson 2011). 
This paper proceeds as follows. In the next section, we introduce a framework to examine household responses to a partial schooling subsidy. Section III describes the context and program. Section IV discusses the data and our empirical strategy. Section V presents results on the impact of Pantawid on children's schooling and work, as well as various alternative channels, and compares the effects of Pantawid with those of programs that fully offset schooling costs, including Prospera, to highlight the role of the subsidy size. Section VI offers concluding thoughts.

\section{Schooling and Child Work Decisions in the Presence of a Subsidy}

The literature exploring household child labor decisions generally treats education and child labor as substitutes. For instance, Basu and Van (1998) assume that children work only to support household subsistence (the so-called luxury axiom), and Baland and Robinson (2000) posit a tradeoff between child labor and human capital accumulation. Most of the empirical evidence on schooling and child labor supports this view (Beegle, Dehejia, and Gatti 2006; Bourguignon, Ferreira, and Leite 2003; Edmonds and Schady 2012; Ferreira, Filmer, and Schady 2009; Manacorda 2006; Ravallion and Wodon 2000; Schady et al. 2008). However, as we show, since the time allocated to school and work for pay can be adjusted on both the extensive and intensive margins, complementarities can arise when households are offered an education subsidy that only partially offsets education expenditures. In that case, we may observe compensatory behaviors as poor (and adult labor constrained) households need to supplement the partial subsidy if they wish to enroll their children. A brief conceptual framework describes how such compensatory behavior can arise.

Most models of the child labor decision explore the tradeoff between current household income and the future income of the child, as determined by lumpy investments in schooling. Several studies present theoretical explanations for why households may underinvest in children's education and examine how a CCT may affect this investment decision. For instance, Das, Do, and Özler (2005) and Fiszbein and Schady (2009) provide comprehensive overviews of the theoretical underpinnings of CCT design. The central question of this paper is somewhat different in that it concerns the household's response to an offered schooling subsidy after an initial decision on child labor allocation has already been made. Possible responses include an asset drawdown, an increase in adult labor supply, a shift in consumption patterns, or an increase in child labor. In so far as the only scenario observed is an increase in child labor, we explore a conceptual framework - described in detail in Online Appendix 1-that focuses on this scenario and identifies how and for whom this increase might arise. ${ }^{6}$

We adapt a simple two-period overlapping generation model of a unitary household to highlight how the presence of fixed schooling costs and nonconvexity in the time and budget constraints, generated by a minimum amount of time that must be devoted to school attendance, can lead to a complementarity between education and child labor in

6. The Online Appendixes are available online at http://jhr.uwpress.org. 
the presence of a partial schooling subsidy. Salient determining factors are the relative size of the subsidy vis-à-vis the cost of schooling, and the strategies available to the household to take up the subsidy and enroll the child in school.

It is important to note that this type of behavioral response need not arise in wealthier populations, where fewer households require subsidies to enable children's school attendance and the households that do have a more diversified set of strategies to take up a partial subsidy. Therefore, this framework does not attempt to present a global model for all child schooling and work decisions, but rather to understand the observed shifts in child labor after the onset of Pantawid.

\section{Background and Study Context}

\section{A. Education and Child Labor in the Philippines}

Recent (2011) ILO survey data show that 95 percent of 10- to 14-year-old Philippine children are in school and that 13 percent of children in the same age range are engaged in economic activities (Understanding Children's Work 2015). About 85 percent are in school only, 11 percent combine school and work, 3 percent are idle (that is, in neither in school nor in work), and 2 percent are in work only. Boys are more likely to work than girls (15 percent versus 10 percent) and somewhat less likely to be in school (93 percent versus 97 percent). ${ }^{7}$ Children in this age range are not legally allowed to engage in economic activities in the Philippines, although the enforcement of such laws has been underresourced, at least until the establishment, in 2015, of an interagency council to enforce child labor laws (U.S. Department of Labor 2016).

\section{B. The Program}

Pantawid aims to support poor households in satisfying their consumption needs and to encourage investment in their children's education and health. The program began in 2008 with the first enumeration of potential beneficiary households through a listing exercise that collected several sociodemographic and household asset indicators to construct a proxy means test (PMT) score. Households were eligible for the CCT if their baseline PMT score fell below the poverty threshold of approximately US\$2.15 per capita per day (in 2011 dollars) and the household included a pregnant woman or at least one child under the age of 14 . The first beneficiary households enrolled and began receiving benefits in the same year. The program has since been expanded and now covers about 4.5 million households.

7. The self-declared reasons for children's participation in economic activities are varied: a substantial number of children work to help in the household-operated farm or business ( 53 percent) or to otherwise support family income ( 20 percent), while a smaller fraction works to gain experience in the labor market (10 percent) or to appreciate the value of work (5 percent). While school attendance rates are comparable between rural and urban areas, rural child employment rates are higher (15 percent versus 8 percent). In rural areas, about 82 percent of children aged 10-14 are in school only, 13 percent combine school and work, and 3 percent each are idle and in work only. 
Pantawid provides both education and health grants. The monthly education grant of 300 Philippine Pesos (roughly US\$7) ${ }^{8}$ is offered to children aged 6-14 who attend primary or secondary school regularly (at least 85 percent of school days each month). The education grant is provided for up to three children per household and for 10 months a year. ${ }^{9}$ The lump sum monthly health grants of 500 Philippine Pesos (roughly US $\$ 11.50$ ) are provided to beneficiary households on the condition that pregnant women and children up to the age of five regularly attend health clinics, children aged 6-14 receive deworming treatment, and the household member receiving the cash transfers (or their spouse) attend "Family Development Sessions" organized by the implementing agency, the Department of Social Welfare and Development. ${ }^{10}$ In our study sample, the average household has 2.6 children, which translates to a maximum monthly transfer of US $\$ 30$, representing about 20 percent of the average beneficiary's monthly household income (see World Bank 2013).

Both the theoretical framework and our interpretation of the empirical results rely on the beneficiary's expectation of enforcement of the schooling condition and not necessarily on the actual enforcement of the condition. While we do not have data on the enforcement of conditions, the program was designed and publicized as conditional. Administrative data show that the average monthly amounts transferred to our sample (US\$18.50) were significantly smaller than the US\$30 maximum for which households were eligible, which may be indicative of conditions being at least partially enforced. Even if program conditions were not consistently enforced during the first years of the pilot stage program, beneficiaries could not have known with certainty whether conditions would be enforced. Hence, noncompliance would have entailed the risk of loss of benefits in the minds of the study subjects. Finally, as Benhassine et al. (2015) show in Morocco, even a "nudge" or an unenforced condition can be enough to induce beneficiaries to comply.

\section{The Evaluation Design}

A village-randomized evaluation was jointly designed by the World Bank and the Philippine Department of Social Welfare and Development. In October 2008, 130 villages were randomly allocated to treatment and control arms of 65 villages each stratified by eight municipalities. The number of villages was chosen based on power calculations for three primary outcomes: school attendance of children aged 6-14, household consumption, and health facility visits. Data for the PMT were collected in all 130 villages from October 2008 to January 2009, and in April 2009 eligible households in the treatment villages began receiving transfers.

Since our conceptual framework suggests that the poorest households are the most likely to exhibit increases in child labor and education in response to a partial schooling subsidy, it is useful to note that these experimental villages represent the poorest villages in the poorest municipalities in the country-the PMT eligibility threshold of US $\$ 2.15$ per capita per day is barely above the World Bank's US\$1.90 per day poverty line.

\footnotetext{
8. All amounts related to the Philippines in the remainder of this paper are in 2011 U.S. dollars, the year in which the followup data were collected.

9. While the amounts mentioned above here are monthly, payment is made every two months.

10. The focus of these sessions rotates on a monthly basis but covers topics such as good parenting practices, general health and nutrition, and household management.
} 
Indeed, eligible households in the 130 evaluation villages had an average per capita income of approximately $\$ 1.50$ per capita per day, 11 percent lower than the average per capita income in the other program areas from this period.

\section{Data and Methods}

\section{A. Data}

We rely on four sources of data collected as part of the Pantawid evaluation. Our primary data source is a followup household survey conducted in October and November of 2011 - two and one-half years after the start of the intervention and during the middle of the 2011-2012 school year. In each of the 130 villages in the evaluation, survey data were collected from a random sample of both eligible and ineligible households in treatment and control communities. ${ }^{11}$

This survey covered a range of topics, including school attendance by children aged 6-17 and work by children aged 10-17. Questions on children's school participation were addressed to the child's mother, guardian, or main caregiver, while the questions on work were addressed to the child herself. Children were asked not only about current work but also, albeit in less detail, about work prior to the start of the program for the calendar years 2007, 2008, and 2009. We use these recall data to explore baseline balance in child work as the baseline does not contain this information. Online Appendix 2 explains how we construct our outcome variables based on this data.

The second source of data is the baseline assessment of household-level demographic and socioeconomic measures used to construct the PMT score. We use these data to assess the balance of key baseline characteristics across treatment and control communities at baseline. Our third data source is a survey administered to village leaders concurrently with the household survey, which includes an assessment of the average daily wage of a male laborer in the village as well as measures of community access to services, such as the distance from the village hall to the nearest public primary and secondary schools. Finally, we use administrative data on the monthly amounts transferred to beneficiary households over the evaluation period.

\section{B. Estimation Strategy}

We exploit the cluster-randomized treatment assignment to identify the impact of the cash transfer program on both children's education and work. In our preferred specification, presented below, we estimate the intent-to-treat (ITT) effect of the program by regressing the outcome of interest on the indicator variable for treatment while controlling for municipality, which is the stratification variable, and age dummies where appropriate:

$$
Y_{i v}=\beta_{0}+\beta_{1} * T_{v}+\boldsymbol{\beta}_{\mathbf{2}}{ }^{\prime} \boldsymbol{X}_{\boldsymbol{b}}+\boldsymbol{\beta}_{\mathbf{3}}{ }^{\prime} \boldsymbol{X}_{i v \boldsymbol{b}}+\varepsilon_{i v}
$$

11. In each village, the survey was administered to 10 poor households (those with a PMT score below the eligibility threshold) with children aged 0-14 and/or a pregnant woman, 10 nonpoor households with eligible children and/or pregnant women, five poor households without eligible children or pregnant women, and five nonpoor households without eligible children or pregnant women. 
Here $Y_{i v}$ is the outcome of interest (for example, school or work) for child $i$ in village $v$ at followup, $T_{v}$ is the indicator variable taking the value 1 for treatment villages, $\boldsymbol{X}_{\boldsymbol{b}}$ is a vector of stratification variables measured at baseline (denoted by $b$ ), $\boldsymbol{X}_{\boldsymbol{i v b}}$ is a vector of age dummies in regressions at the child level, and $\varepsilon_{i v}$ is the error term. The coefficient $\beta_{1}$ estimates the ITT effect of the program using OLS. In a series of tables in the Online Appendix, we examine whether the precision of our estimates improves when we include control variables and whether results are robust to using the following alternative models: Probit, Logit, and panel regressions with individual fixed effects (treating the 2007, 2008, and 2009 recall data as baseline measurements). All standard errors are clustered at the village level.

\section{Sample Definition}

We focus on children aged 10-14 as they are the youngest children eligible for the education grant for whom both schooling and work data are available. We further restrict our sample to children from households that are below the poverty threshold and therefore eligible to participate in Pantawid, which yields a final sample of 1,264 children: 637 from 411 households in treatment villages and 627 from 422 households in control villages. $^{12}$

Online Appendix 3 examines the validity of the village-level randomized assignment of Pantawid across all available baseline individual, household, and community characteristics. We test for balance by regressing the vector of these characteristics on the treatment indicator, clustering standard errors at the village level. There are no statistically significant mean differences between the treatment and control groups across the covariates considered.

Administrative data show that 605 of 637 (95 percent) of the children from treatment villages are from households that actually participated in the CCT program. In contrast, none of the children from control villages belong to households that participated. Given the high rate of compliance with treatment assignment, the ITT effects reported are not substantively different from estimates of treatment on the treated (discussed in further detail below).

\section{Results}

\section{A. Descriptive Statistics}

Table 1 presents mean values in the control group for the outcome variables considered. School attendance rates among children aged 10-14 are high-almost 90 percent attend school, and 80 percent do so regularly-but lower than the national average because the evaluation study sample was drawn from the poorest areas of the Philippines.

12. Household-level attrition from the baseline sample was 11.4 percent ( 80 out of 624 households) in treated villages and 11.2 percent ( 80 out of 634 households) in control villages, with no evidence of a significant difference by treatment status (see also Online Appendix Table 1, reproduced from World Bank 2013). 


\section{Table 1}

Descriptive Statistics: Children from Pantawid Control Communities

Mean Values

Extensive margin:

Attends

0.882

Attends primary school

0.651

Attends secondary school

0.231

Attends regularly

0.793

Attends primary school regularly

0.579

Attends secondary school regularly

0.215

Worked in past 12 months

0.202

Pay and location:

For pay, outside own household

For pay, inside own household

0.031

Without pay, outside own household

0.040

Without pay, inside own household

0.091

Types of occupations:

Laborers and unskilled workers

0.144

Farmers, forestry workers, and fishermen

0.079

Other

0.008

Worked in past seven days

0.158

Pay and location:

For pay, outside own household

0.066

For pay, inside own household

0.017

Without pay, outside own household

0.028

Without pay, inside own household

0.080

Types of occupations:

Laborers and unskilled workers

0.098

Farmers, forestry workers, and fishermen

0.068

Other

0.000

Mutually exclusive combinations of school and work

In school only

In work only

0.038

In school and in work

0.164

Neither in school nor in work

0.073

Worked while school was in session

0.094

Intensive margin:

Days attended school past two weeks

Unconditional

Conditional on attending school

8.6 
Table 1 (continued)

Mean Values

Days worked in past 12 months

Unconditional

Conditional on any work

Days worked for pay, outside own household in past 12 months

Unconditional

Conditional on any work

Hours worked in past seven days

Unconditional

Conditional on any work

Hours worked for pay, outside own household in past seven days

Unconditional

0.7

Conditional on any work

10.6

Notes: Estimates based on 656 children aged 10-14 from eligible households in control villages.

Most children in the 10-14 age range are in primary school, although about 20 percent are already in secondary school. A substantial proportion, about 20 percent, worked in the 12 months before the interview and about 16 percent in the seven days prior to the interview. Conditional on any work, children work about 30 days a year and about 12 hours a week. Children are as likely to report working for pay outside the household as working without pay inside the household. Most of the work carried out by children is unskilled, and most children who work (about four in five) are also in school. A sizeable group of children (about 7 percent) neither worked nor attended school in the 12 months prior to the interview. As we show below, the cash transfer program had a particularly strong effect on the schooling and labor supply of this last group of children.

\section{B. Impact of Pantawid on Education}

A key goal of Pantawid is to improve children's school participation. Table 2 presents estimates of the effect of the cash transfer program on the school participation of children aged 10-14. Overall attendance increased by four percentage points relative to a control mean of 89 percent (Column 1). Regular attendance, defined as attendance of at least 85 percent of school days in the two weeks prior to the interview, increased by nine percentage points (over a control mean of 80 percent, Column 4). This increase occurred especially in primary school (Columns 2-3 and Columns 5-6). The reported number of days children attended school in the two weeks prior to the interview increased by approximately a full day, from 7.5 to 8.5 (Column 7). The increase in the number of days children attended school reflects changes in both the probability of school attendance and the number of days attended in the two weeks prior to the interview conditional on 


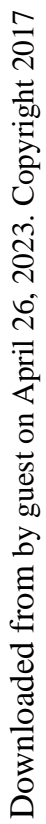

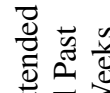

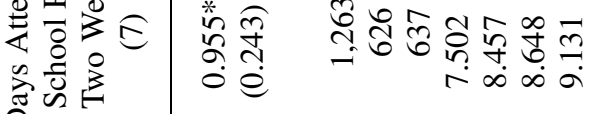

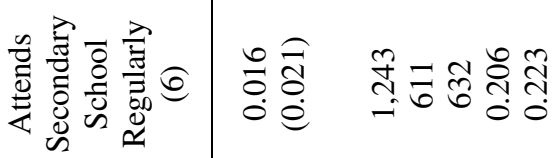

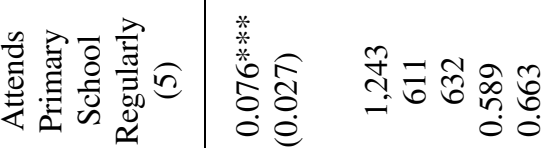

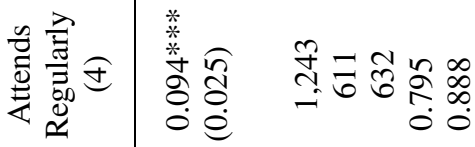

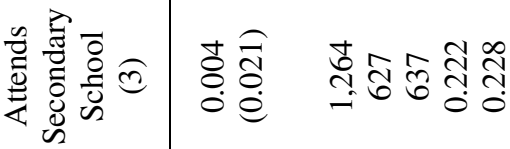

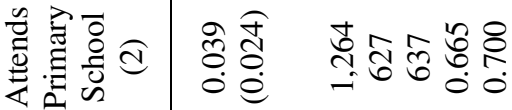

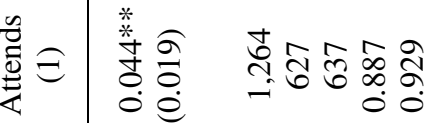

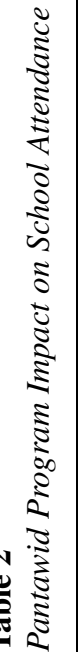

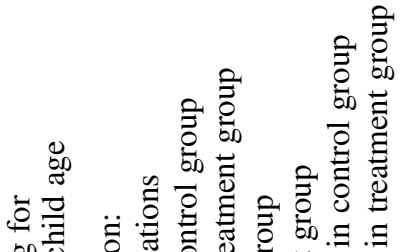

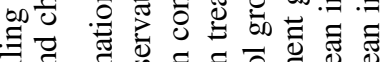

矛 苛

苛灾

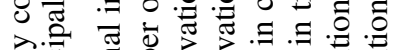

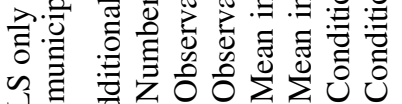

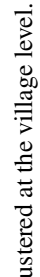

๘ 
having attended school at least one day (presented at the bottom of the table). ${ }^{13}$ Pantawid thus appears to have significantly increased regular primary school attendance.

\section{Impact of Pantawid on Child Labor}

While Pantawid did not explicitly target child work in its choices of conditions or messaging, the program may have had an impact on child work through a variety of channels, as we discuss in more detail below. Table 3 explores such impacts. ${ }^{14}$ The probability of 10- to 14-year-old children engaging in work in the 12 months before the interview increased by four percentage points (Column 2). While not precisely estimated, the point estimate indicates a 20 percent increase over the control mean. ${ }^{15}$ Columns 3-5 of Table 3 show that the increase in work is due solely to an increase in work for pay outside the household - a five percentage point increase over the control mean of 12 percent, significant at the 5 percent level. Work without pay, inside or outside the household, and work for pay inside the household are not significantly affected. Accordingly, as shown in Columns 6-8, children increase their participation in laboring and unskilled work, while participation in other work, such as farming and fishing, is not significantly affected. Effects on the number of days worked, including for pay, in the past year are positive but not statistically significant. However, as shown at the bottom of the table, conditional on working, days worked are slightly higher in the treatment group than in the control group. Although we cannot identify working hours separately for children who started working because of the program and those who would work even in the absence of the program, the latter suggests that working hours are similar in both groups.

In Table 4, we examine how Pantawid affected the four mutually exclusive combinations of school only, work only, school and work, and neither school nor work (Columns 1-4, respectively) and whether children worked while school was in session (Column 5). We find that Pantawid causes a four percentage point decrease in the probability of children being neither in school nor work and a six percentage point increase in the probability of children both working and attending school. The probability of children working while school was in session increased by five percentage points. These results suggest the most prevalent behavioral shift caused by the program was a transition from being in neither school nor work to being in both school and in work.

We separately estimate the effects on boys and girls by interacting the treatment variable with gender dummies (results available in Online Appendix Table 2). $F$-tests do not allow us to reject the null hypothesis that the program impact is similar for boys and girls, with both sexes increasing regular school attendance (eight and nine percentage points respectively, Column 2), and the likelihood of being engaged in work for pay outside the household by about five percentage points (Column 4).

13. Of course, given that regular school attendance is a program requirement, these self-reported data need to be interpreted with some care (Baird and Özler 2012). Households may misreport school attendance to ensure that they are not removed from the program even if the responses to the questionnaire were treated as confidential and were not used to check compliance. By emphasizing children's education, the program may also have stigmatized child labor in treated villages, thus leading to a downward bias in our estimated effects on child labor. 14. The outcome measures for work are observed for about 93.4 percent of children $(94.6 \%$ in the treatment group and $92.1 \%$ in the control group). Online Appendix Table 11e shows that reported pre-intervention child work is lower in treated communities than in control communities.

15. This coefficient reaches traditional levels of significance if we include covariates to increase precision (as shown in Online Appendix Table 4). 


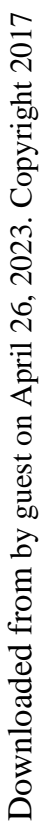

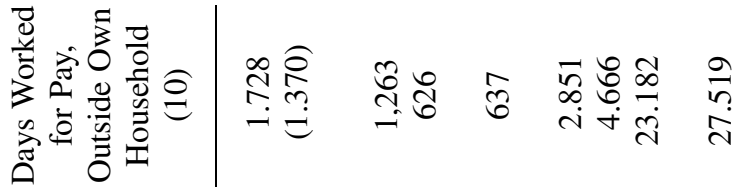

515

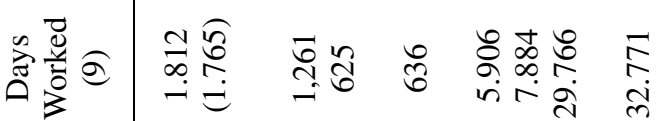

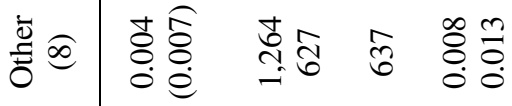

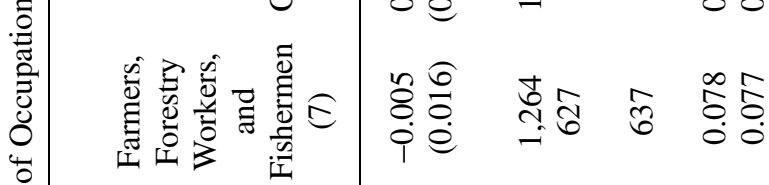

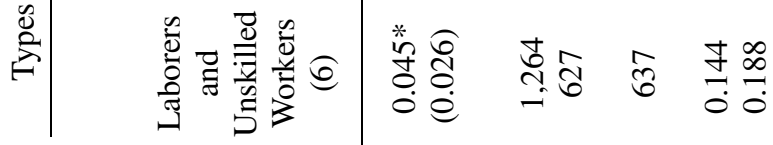

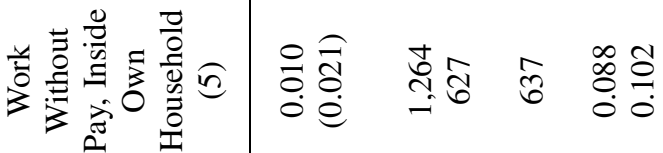

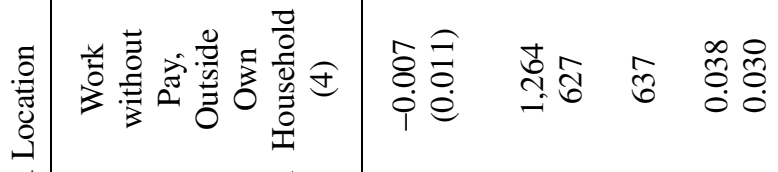

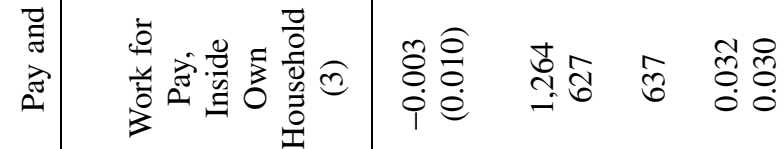

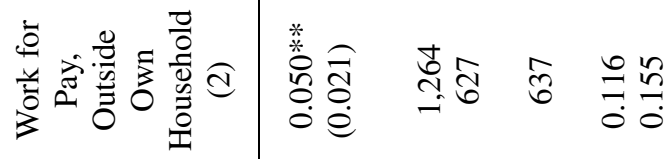

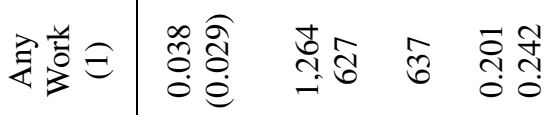

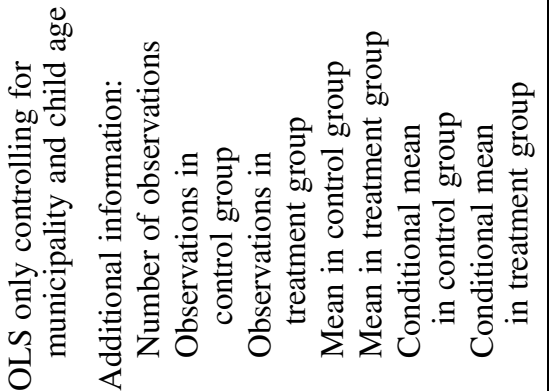

do 


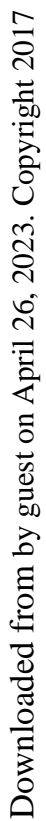

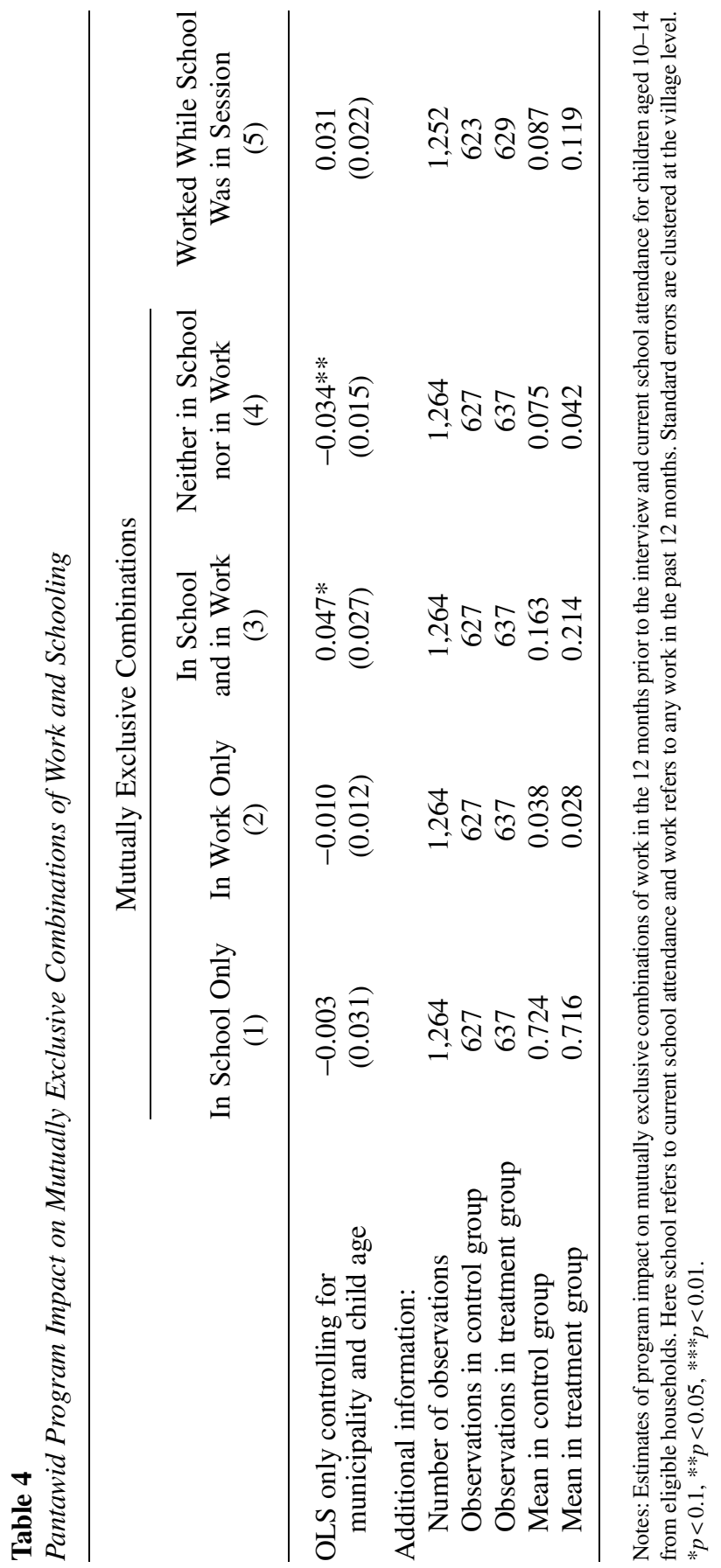




\section{Robustness of the Reported Impacts of Pantawid on Child Schooling and Labor}

We then examine whether the inclusion of control variables increases the power of our hypothesis tests and the extent to which the results presented above are sensitive to the use of alternative estimation procedures, sample trimming, and alternative reference periods. Our specification with control variables augments the original regression specification as follows:

(2) $Y_{i v}=\beta_{0}+\beta_{1} * T_{v}+\boldsymbol{\beta}_{\mathbf{2}}{ }^{\prime} \boldsymbol{X}_{i v b}+\boldsymbol{\beta}_{\mathbf{3}}{ }^{\prime} T_{v} *\left[\boldsymbol{X}_{i v b}-\mu\left(\boldsymbol{X}_{v b}\right)\right]+\boldsymbol{\beta}_{\mathbf{4}}{ }^{\prime} X_{i v b \text { Missing }}+\varepsilon_{i v}$.

Here $\boldsymbol{X}_{\boldsymbol{i v b}}$ is a vector of individual, household, and village-level control and stratification variables (municipalities) measured at baseline (denoted by $b$ ). These controls, described further in Online Appendix 3, include the interaction of the treatment variable $T_{v}$ with the vector $\left[\boldsymbol{X}_{\boldsymbol{i v b}}-\mu\left(\boldsymbol{X}_{\boldsymbol{v} b}\right)\right]$ to address concerns of regression adjustment presented by Freedman (2008a, 2008b) and discussed in Lin (2013). The vector $\mu\left(\boldsymbol{X}_{\boldsymbol{v} \boldsymbol{b}}\right)$ contains the averages of the control variables across both treatment and control groups. When a control variable is missing for individual $i$, we set both the relevant element of the vector $\boldsymbol{X}_{\boldsymbol{i v b}}$ and the element of the vector $T_{v} *\left[\boldsymbol{X}_{\boldsymbol{i v b}}-\mu\left(\boldsymbol{X}_{\boldsymbol{v} b}\right)\right]$ equal to -1 . We let the elements of the vector $\boldsymbol{X}_{\boldsymbol{i v b} \text { Missing }}$ take the value 1 if the relevant control variable is missing and 0 otherwise.

Robustness tests also reconsider the following choices made above: (i) the use of OLS instead of binary models like Probit or Logit, (ii) the inclusion of 43 children who were neither children nor grandchildren of the household head and may lead to concerns around endogenous changes in household composition, (iii) reporting village-level ITT estimates instead of treatment-on-treated effects and for work outcomes, (iv) using a 12month recall instead of seven-day recall, and (v) using cross-sectional data on current work rather than fixed-effects regressions using recall data on work in previous years. ${ }^{16}$ We specify the fixed-effect regressions as follows:

$$
Y_{i v t}=\beta_{0}+\beta_{1} * T_{v t}+d_{i}+d_{2008}+d_{2009}+d_{2011}+\varepsilon_{i v t} .
$$

Here, $Y_{i v t}$ is the outcome variable for individual $i$ from village $v$ at time $t$ (that is, 2007, 2008,2009 , or 2011), $T_{v t}$ is the treatment variable (1 for treatment villages in 2011, 0 otherwise), $d_{i}$ is an individual fixed effect, and $d_{2008}, d_{2009}$, and $d_{2011}$ are time fixed effects.

Online Appendix Table 3 shows the effects on school enrollment and attendance, while Online Appendix Tables 4 and 5 present the effects on child work and the transition from idleness to joint schooling and work, respectively. As the first row of each of these tables shows, point estimates do not change in magnitude or sign but are more likely to be statistically significant when we include covariates. Impact on any work in the 12 months before the interview, for instance, is statistically significant when we include controls. These tables further illustrate the robustness of our results to the use of binary response models instead of OLS, as well as child-level fixed effects using the 2007, 2008, and 2009 recall data as our baseline measurement. While some standard

16. We do not have recall data on schooling and duration worked, so we cannot establish the robustness of those estimates using fixed effects. 
errors are marginally larger, all results are robust in magnitude and precision to the exclusion of children who are neither the biological child nor grandchild of the household head. Finally, Panel B of Online Appendix Table 4 confirms that the estimated increase in work is broadly robust to seven-day recall instead of a 12-month recall. For this alternative reference period, participation in work, unskilled work, and work for pay outside the household all increase across most specifications, suggesting that our results are not driven by differential measurement in the longer recall period.

\section{E. Working to Support School Attendance?}

To examine potential explanations for the increase in work for pay outside the home, we start by considering transfer sizes, schooling costs, and children's earnings. If children work to make up the shortfall in the net cost of education, we would expect the income they earn to represent a substantial share of this shortfall. For this analysis, we focus on primary school attendance, which increased significantly. School expenditure averages US\$73 for every 10- to 14-year-old child enrolled in primary school in control communities and US\$86 in treatment communities. The difference in school expenditures between control and treatment arms in the full sample suggests that school attendance is costlier for children who switch from idleness to the school-and-work state because of Pantawid. Assuming that inframarginal children in treatment communities-that is, those who are in school even in the absence of the program - exhibit the same schooling costs as those in control communities, the observed US $\$ 13$ difference in education costs for the treatment and control groups in the overall sample would reflect an average education cost as high as US\$195 for compliers.

Bounded by the interval ( $\$ 86, \$ 195)$, total education expenditures for compliers thus appear to be well above the maximum annual per-child education transfer of approximately US $\$ 70$. The difference between education expenditures and transfers actually received by beneficiary households according to the administrative data is higher still. Regressing administrative data on total transfer amounts received by households on the number of children aged 6-14 in primary school, in secondary school, and a constant, we find that households received about US $\$ 115$ in a calendar year if no children attended primary or secondary school, which is roughly equal to the annualized health grant. Beneficiary households report receiving an additional US\$55 for every child in primary school.

The amount earned by children represents a substantive share of the shortfall in schooling costs. Conditional on engaging in any work for pay, enrolled children in control communities report earning US\$22 annually. The same value for children in treatment communities is US\$43 annually. Assuming that inframarginal children in control and treatment communities exhibit the same annual income, the observed difference in average earnings of US $\$ 21$ between treatment and control communities corresponds to average earnings of US $\$ 75$ by complying children. This income earned by compliers would hence cover roughly one-half of the upper bound of education costs net of the transfer, approximately equaling US $\$ 140 .^{17}$

17. Note that this shortfall may be an upper bound on the true shortfall if inframarginal children increased their school expenditure or reduced their participation in work for pay. 
Examining the behavior of siblings of children aged 10-14 lends further support to the hypothesis that children work to support their school attendance. We turn first to the eligible older siblings (ages 15-17) of the children aged 10-14 in our core sample. Panel A of Online Appendix Table 6 shows that the school participation of these older siblings is not affected, but that these children, too, increase their participation in work for pay outside the household, perhaps helping to offset the education expenditure for their younger siblings. Indeed, Panel A of Table 5 shows larger increases in school and work by children aged 10-14 with older siblings than among those without older siblings, a finding comparable to the negative displacement result reported in Barrera-Osorio et al. (2011).

If the lump-sum health grant was used by households to meet some of the schooling cost shortfall left by the education grant, then the lump-sum transfer should be most effective at increasing enrollment and attendance when there are no other school-age children in the household - the greater the number of enrolled children, the greater the dilution in the impact of the lump-sum health transfer for each child. Consistent with such a dilution, Panel B of Table 5 indeed shows that children with no enrolled siblings are more likely to be enrolled in school only and the probability of being enrolled in school decreases with the number of in-school siblings.

\section{F. Alternative Compensatory Behaviors}

The evidence thus far is consistent with the shortfall in education costs met by an increase in child labor as well as, perhaps, increased spending from the health grant and shifts in the working patterns of older siblings where applicable. Further analysis suggests that the households did not rely on other compensatory mechanisms to cover the additional cost of schooling. First, adults did not adjust their labor supply, measured for the seven days prior to the interview, as a result of the CCT: Table 6 examines whether the program affected the probability (i) that any adult household member was involved in agricultural activities, a family-owned nonfarm businesses, or fishing and (ii) that adult members in these households worked and whether they worked for a private household or enterprise, worked for the government, or on their own or householdowned farm or nonfarm business. Following the estimation strategy outlined above, we find no indication that the program affected household-level microentrepreneurial activities or the overall likelihood of adult work. However, there is some evidence of substitution out of self-employment into wage work, which may indicate a need for cash income. These results are consistent with our assumption in the conceptual framework discussed in Online Appendix 1 that these households are adult labor constrained (60 percent of all adults in these households were already engaged in economic activities in the absence of the program).

Second, household expenditure, other than on health and education, does not appear to have changed, suggesting that changes in household consumption patterns are not driving our results. Table 7 explores the relative expenditures of households with children in our core sample. The point estimates for education and health expenditures are relatively large (suggesting increases of 18 and 22 percent), although these are not precisely estimated. Approximately 20 percent of these households had any savings, and the average amount saved was $\$ 11$, suggesting that this is a savings-constrained 


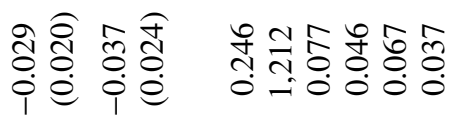

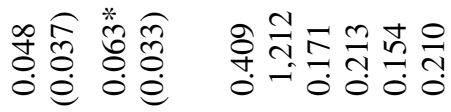

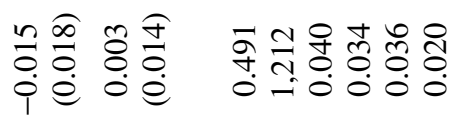

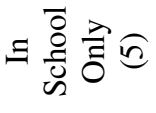

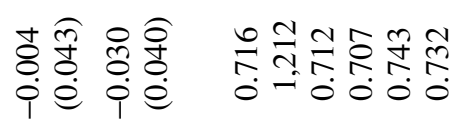

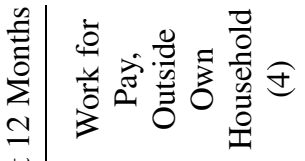

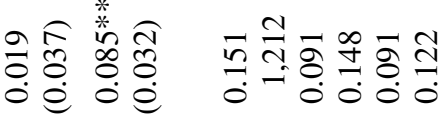

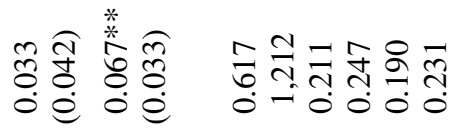

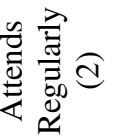

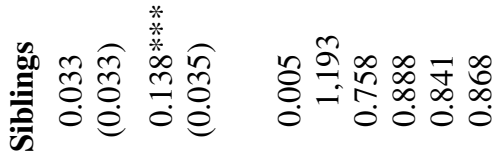

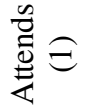

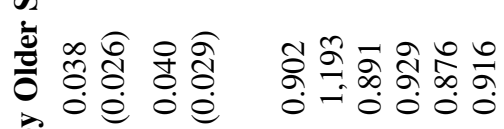

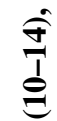

$\stackrel{\overparen{0}}{.00}$

交

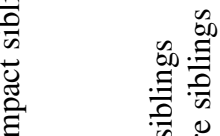




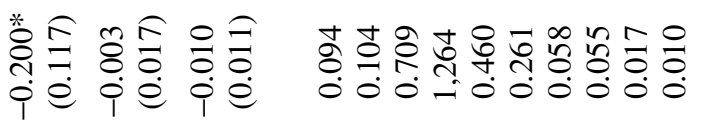

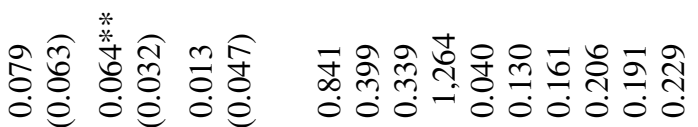

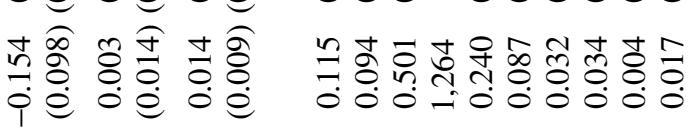

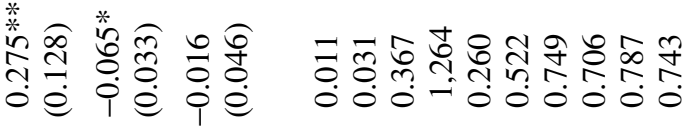

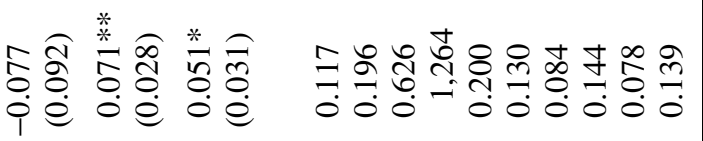

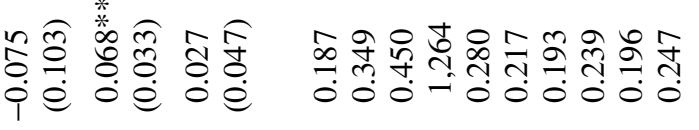
52

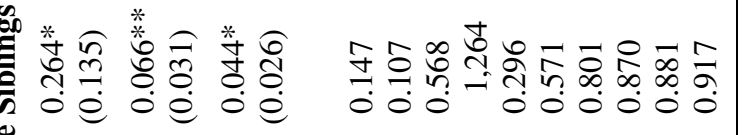
…

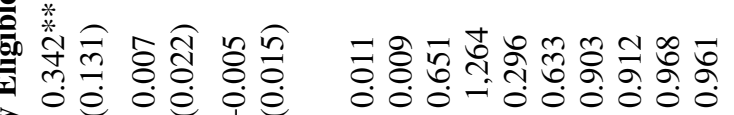
3

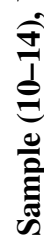

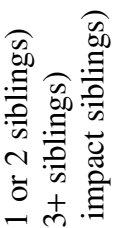

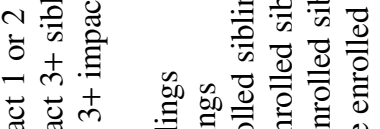

ปั้

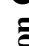

政

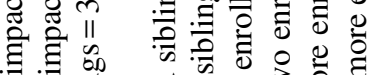
iI II.

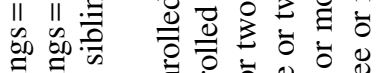

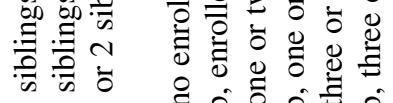
00 -

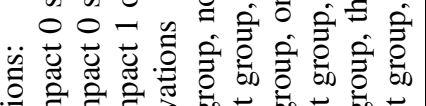

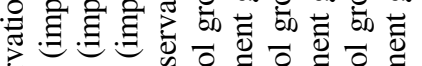

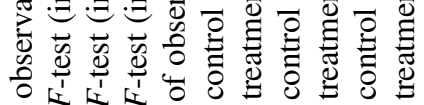
等

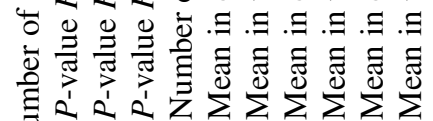




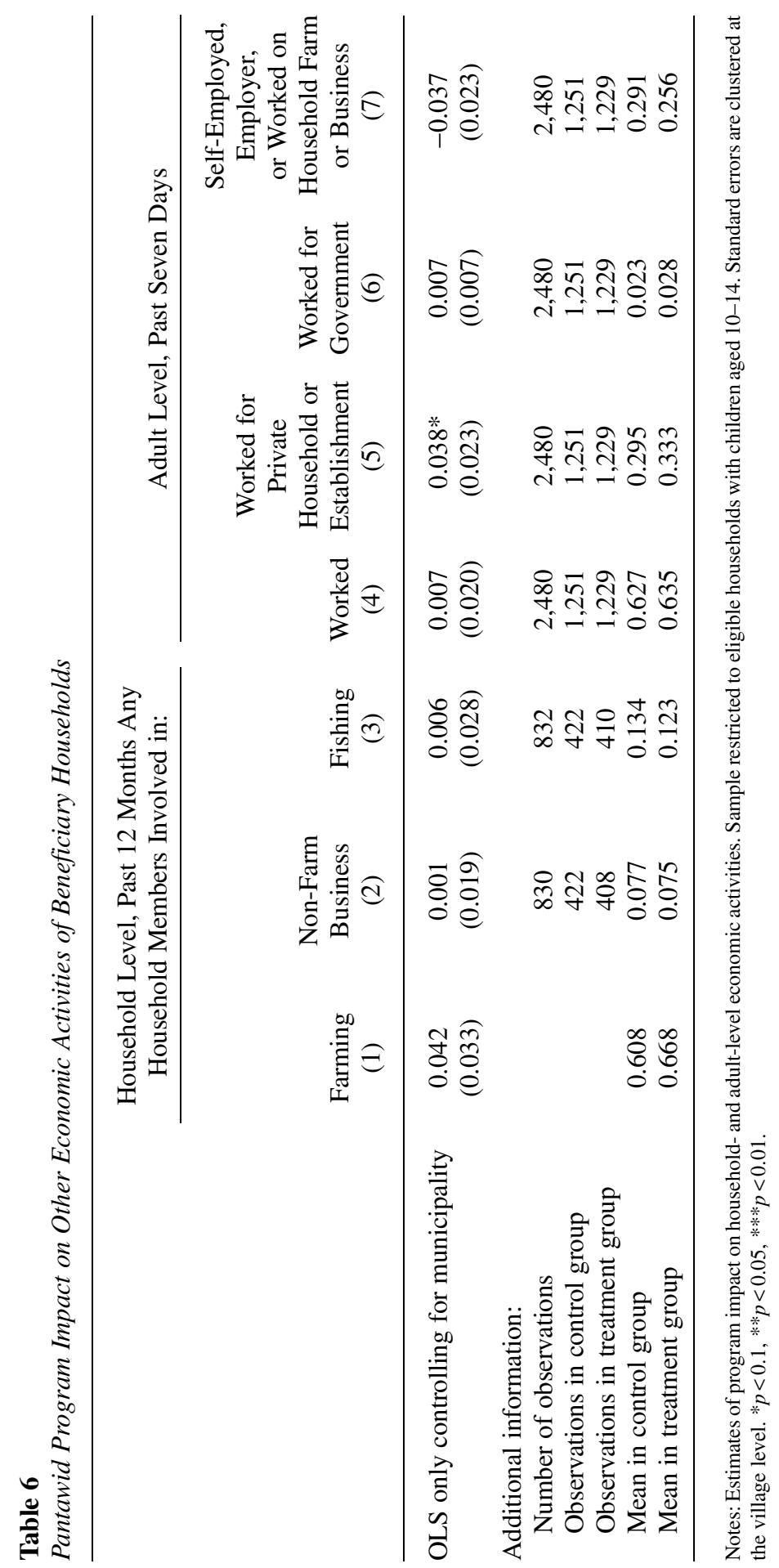




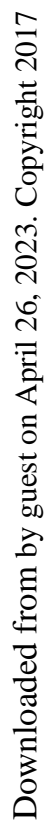

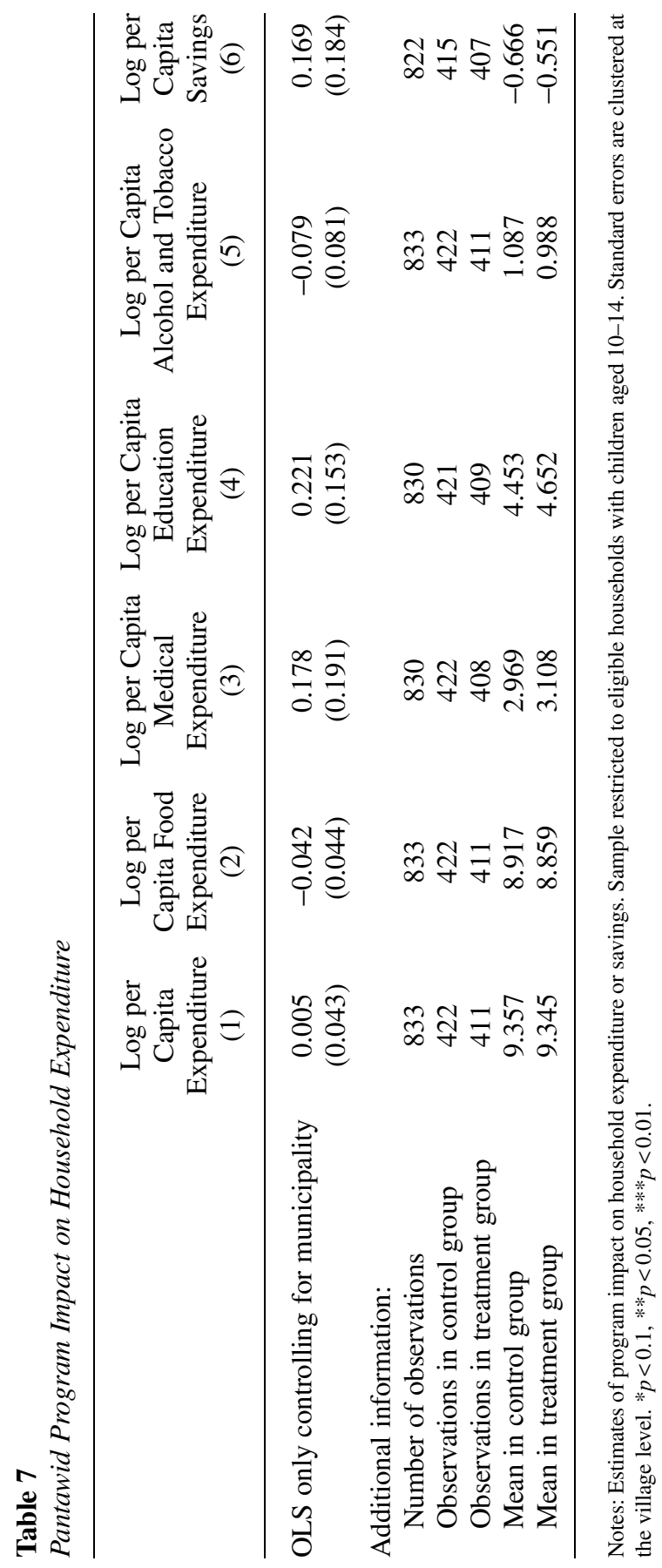


population that would find it difficult to cover additional education expenditures from savings. All told, these findings indicate that households did not use other compensatory behavior to cover the shortfall in child schooling costs.

\section{G. Alternative Explanations for the Rise in Child Work}

This section examines a range of potential alternative explanations for the increase in child work. A first possibility is that the inflow of cash led to changes in the local economy (Angelucci and De Giorgi 2009), for example, positive spillovers on nonbeneficiaries living in Prospera villages) that increase the returns to work or labor demand in treatment communities. To understand whether the program resulted in such general equilibrium effects, we examined whether wages and economic activity of ineligible households were affected by the program, but find no evidence for such an effect (Online Appendix Table 7). A second possibility is that household composition changes in response to the cash transfer. For instance, the additional income available to the household may induce increased fertility, in turn decreasing adult female labor supply and increasing demand for child work, but we do not find any evidence that Pantawid affected family composition (Online Appendix Table 8). A third possibility is that school attendance opens up new opportunities for children to work. This may occur if there are few employment opportunities close to the home of the child, but commuting to a school near a market (or another economic hub) allows the child to work. However, Online Appendix Table 9 shows that, if anything, longer distance to the nearest market is associated with a higher probability of being in work. A fourth option would be that children learn about work opportunities from their peers in school. However, given that the villages in our sample are small (215 households on average in the baseline PMT data), this mechanism appears unlikely.

Finally, cash transfer programs may improve children's health, thus increasing their capacity for work and school participation. Indeed, Kandpal et al. (2016) find that Pantawid helps to keep the youngest children healthy, one of the stated aims of the program. In treatment villages, children up to the age of five (for whom extensive health data, including anthropometric indicators, were collected) were less likely to be stunted, more likely to eat protein-rich food, and more likely to receive preventative health services. Older children's health may have improved due to increased household expenditure on health and nutrition. The program also required regular deworming for older children, which may have improved schooling outcomes (Baird et al. 2016; Bleakley 2007; Miguel and Kremer 2004). If this mechanism were driving our results, we would expect improvements in child health to have similar effects on work for pay outside the household and work without pay inside the household. However, we do not observe an impact on the latter. In addition, Online Appendix Table 10 shows no significant association between parent-reported offer of deworming pills at school to children aged 10-14 and child labor supply in the control areas. ${ }^{18}$ Moreover, as we discuss below, similar programs in other contexts, including Prospera in Mexico, improved child health without increasing child work.

18. Deworming was offered at school, with 75 percent of children aged 10-14 in control areas being offered them. We do not find any effect of the deworming offer on regular school attendance (result not shown). 


\section{H. The Impact of More Generous Education Subsidies}

The evidence presented above suggests that the increase in child work is largely the result of a partial grant for the full cost of education. This observed increase in children's participation in paid work contrasts with evidence from other cash transfer programs, which document either a significant decrease or no change in child labor because of the transfer (reviewed in de Hoop and Rosati 2014). However, Online Appendix Table 11 shows that, in virtually all the programs studied, the transfer amount exceeded the full cost of education. The Philippines thus appears to be the first CCT program to experience a slight rise in the rate of child work and is one of the few that did not fully cover the cost of education.

To further illustrate this contrast between Pantawid and more generous CCT programs, we examine the schooling and child labor effects of the Mexican Prospera program when it was first implemented in the late 1990s (Parker, Rubalcava, and Teruel 2008). This comparison is insightful for three reasons. First, the rural target populations of the two programs had comparable levels of school attendance and child labor: the 1996 Mexican National Survey of Household Income and Expenditure (ENIGH) shows that 84 percent of children aged 12-14 were in school while 15 percent were engaged in economic activities with boys, especially in rural areas, being almost twice as likely to work as girls. About 76 percent of children were in school only, 9 percent were idle, 8 percent combined school and work, and 7 percent were in work only. Second, Pantawid was explicitly modeled after Prospera in terms of both conditions and relative transfer size to household income (Barber and Gertler 2008; Skoufias and Parker 2001). The experimental phases of both programs were targeted at the poorest communities with household poverty defined by a PMT (World Bank 2013). However, in contrast to Pantawid, the education grant from Prospera was explicitly "set to cover the opportunity costs for students, estimated on the basis of observed children's incomes" (Fiszbein and Schady 2009, p. 182) and the maximum-possible education grant covered about twothirds of the earnings of a full-time working child (Schultz 2004). Third, the pilot phase of the (then Progresa, and now Prospera), program was accompanied by a similar cluster-randomized evaluation design (Parker, Rubalcava, and Teruel 2008). In the late 1990s, 495 rural localities were randomly allocated to an early treatment group (313 localities) and a late treatment group (182 localities), with take-up rates of approximately 97 percent (Ozer et al. 2011). We use the baseline household survey administered in 1997, followup household survey administered in 1999, as well as 1999 locality-level information, to construct variables comparable to those used in the Pantawid analysis above (variable construction is described in Online Appendixes 2 and 4).

Replicating the Pantawid estimation procedure, we estimate the effects of Prospera on children's schooling and work based on regression Specification 1. Table 8 presents our estimates of the effects of Prospera on participation in school and work by children aged 10-14. As established in previous studies (Rubio-Codina 2010; Schultz 2004; Skoufias and Parker 2001), we find that Prospera increased school enrollment and attendance by about six percentage points each (Columns 1 and 2). However, in contrast with Pantawid, Prospera reduced the probability of children working for pay by about one percentage point (Column 4) and the probability of children being in neither school nor work by four percentage points (Column 8). 


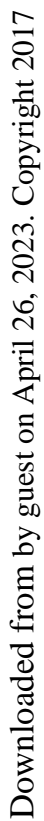

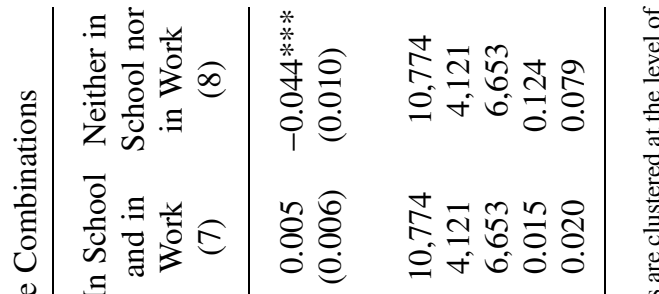

窇

方

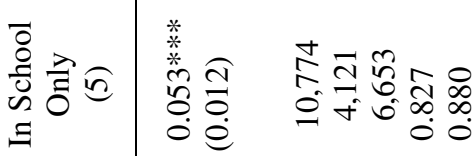

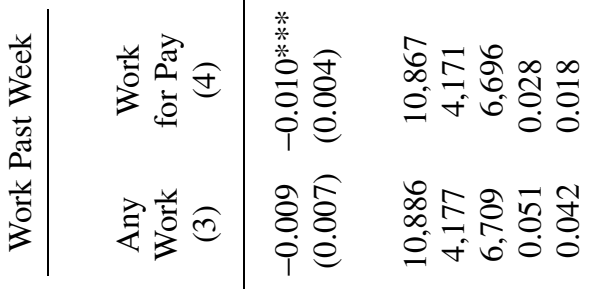

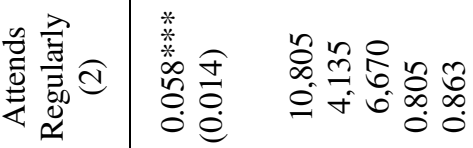

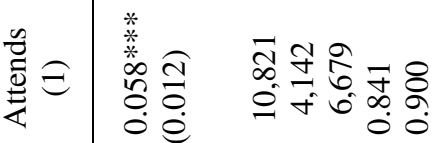

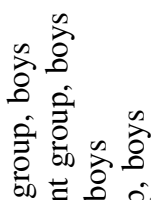

o

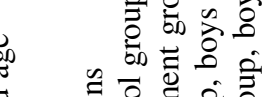

它司

कo

흥

घ $\Xi . \Xi \overline{0}$

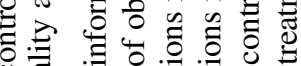

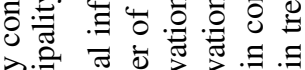

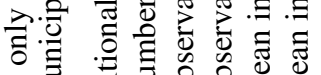

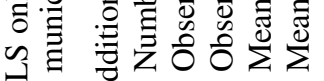

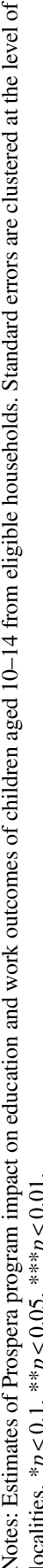


Various other studies show that Prospera resulted in benefits and behaviors that, at least in theory, can increase children's participation in work, including greater household investment in productive activities (Gertler, Martinez, and Rubio-Codina 2012), higher consumption by ineligible households (Angelucci and De Giorgi 2009), and improved children's health (Gertler 2004; Rivera et al. 2004). The fact that Prospera nonetheless lowered children's participation in work is consistent with our hypothesis that the size of the education subsidy relative to schooling cost influences the child schooling and work decision. Further, the fact that Prospera improved child health while reducing their labor participation suggests that, at least in the case of rural Mexico, the relative value of the education subsidy dominates the health channel when it comes to child work decisions.

\section{Discussion and Conclusions}

This paper illustrates how a partial subsidy for a socially desirable good can elicit unanticipated compensatory behavior from complier households. We show that the Philippines' Pantawid cash transfer program, which partially subsidized schooling during its early implementation, generated compensatory behavior in the form of concomitant increases in schooling and participation in paid work by the same children. In particular, Pantawid increased children's participation in work for pay outside the household by about five percentage points, over a control mean of 20 percent. This result appears to been driven by children who would otherwise neither be in school nor in work and stands in contrast with most other cash transfers, including the Mexican Prospera, which increased schooling while decreasing paid work by children. Unlike these other CCTs, Pantawid only partially subsidized schooling. Compliance by children who would not be in school in the absence of the program represented a net cost to the household, leading these children to make up a substantial share of the shortfall through paid work. We rule out several alternative explanations for the increase in child labor including changes in household investments, adult labor supply, and alternative compensatory behaviors, such as reduced household spending. We also address the role of child health and possible declines in the search cost for child jobs, but do not find evidence consistent with these channels principally driving the observed results on work for pay.

This behavioral response to Pantawid is consistent with a theoretical framework that posits child labor as a complement to school participation when the offered subsidy does not cover the full cost of schooling, but is high enough to render part-time child work a useful supplemental strategy. This view of child work as complementary to schooling runs counter to most theoretical treatments of child labor, which presents the two as strict substitutes. Specifically, our findings contrast with the luxury axiom in the child labor model presented in Basu and Van (1998), which stipulates that child labor occurs only if families could not subsist without child labor. Since time allocated to school and work for pay can be adjusted on both extensive and intensive margins, complementarity can arise in the presence of a partial education subsidy, as we observe here.

This study is not without caveats. First, we lack the baseline data to show definitively that children who were idle at baseline switched into paid work and schooling after the cash transfer. However, we show balance at baseline along a rich set of other household 
characteristics. We also do not have data on the health outcomes of the 10- to 14-yearold children in our sample, and therefore can only rule out the potentially positive effects of health improvements through the cash transfer on child labor supply through an ITT analysis of children offered deworming and by comparison to Prospera. Finally, we do not have data on children's social networks, so therefore we cannot completely rule out that going to school provided children with information about job opportunities, which, rather than the size of the transfer, led to the increase in child work.

Findings of this nature present complications for the policymaker's choice of transfer amount in a CCT program. A transfer amount set too high may allocate substantial resources to households who would comply with the conditions even without the transfer, thus raising concerns about the efficiency of the transfer. On the other hand, a lower transfer amount may not induce all eligible population to take up the preferred behavior or may induce households to adopt compensatory activities such as an increase in child labor. The determination of an efficient subsidy level should consider not only program costs but also additional costs incurred by financing such a program (such as deadweight loss) and any cost of private behavior change taken in response to the program. Against these costs stand the anticipated benefits of increased school participation and reduced income poverty. ${ }^{19}$

A back-of-the-envelope calculation of the increase in program costs from increasing the Pantawid education grant to a full schooling subsidy demonstrates these tradeoffs. We estimate above that schooling costs ranged between $\$ 85$ and $\$ 195$, while the reported annual education grant received by families during the pilot was $\$ 70$. To provide a full subsidy, Pantawid would thus have had to pay an additional $\$ 15$ to $\$ 125$ per child in school per year. For our sample of 654 children, this would have meant an increase ranging from 21 to 179 percent in the disbursements for the education grantthe outlay would have gone from $\$ 45,780$ to $\$ 55,590$ for these 654 children if the costs were $\$ 85$ and to $\$ 127,530$ if the costs were $\$ 195$. During the pilot phase, education grants comprised approximately one-half of the potential total transfer value ( $\$ 12.50$ of a maximum of $\$ 25$ per month), and the Philippine government reported spending 90 percent of its Pantawid budget on the health and education grants (Department of Social Welfare and Development 2015). An increase of 21 percent in the outlay for the education grant would thus have translated to a 9.5 percent increase in the overall 2015 program budget of US $\$ 1.3$ billion, while a 179 percent rise in outlays for education grants would have translated to a 80.6 percent budget increase. ${ }^{20,21}$ Without knowing

19. While our framework predicts that transfers smaller than the cost of education can lead to compensatory behavior, policymakers should also consider a variety of contextual factors. For instance, rigidities in minimum working hours and school attendance requirements might make it difficult for children to combine work for pay and school (see Edmonds and Schady 2012), even in the presence of a partial subsidy. Household resource availability is another mediating factor: since the lack of asset wealth is a key factor of the proposed mechanism, we do not expect similar changes in the wealthier communities phased into Pantawid as the program continued to expand its coverage.

20. The risk of child labor may be exacerbated over time because transfer sizes have not kept up with inflation, so the current shortfall in education costs may be higher than estimated here.

21. Since the rise in child labor appears to be concentrated among the poorest households, an alternative approach might be to introduce a differentiated subsidy that falls in value as the estimated income of the beneficiary household rises. While this would mean more complex program implementation, it would decrease the additional program costs required to avoid the increase in paid work by children. 
the nature of the work done by children, we cannot estimate welfare effects, but note that eliminating the increase in child labor reported by this paper would have come at a substantial increase in total program costs.

\section{References}

Akabayashi, Hideo, and George Psacharopoulos. 1999. "The Trade-Off between Child Labor and Human Capital Formation: A Tanzanian Case Study.” The Journal of Development Studies 35(5):120-40.

Angelucci, Manuela, and Giacomo De Giorgi. 2009. "Indirect Effects of an Aid Program: How Do Cash Transfers Affect Ineligibles' Consumption?" American Economic Review 99(1):486-508.

Augsburg, Britta, Ralph de Haas, Heike Harmgart, and Costas Meghir. 2015. "The Impacts of Microcredit: Evidence from Bosnia and Herzegovina." American Economic Journal: Applied Economics 7(1):183-203.

Baird, Sarah, Joan Hamory Hicks, Michael Kremer, and Edward Miguel. 2016. "Worms at Work: Long Run Impacts of a Child Health Investment." Quarterly Journal of Economics 131 (4):1637-80.

Baird, Sarah, Francisco H.G. Ferreira, Berk Özler, and Michael Woolcock. 2014. "Conditional, Unconditional and Everything in Between: A Systematic Review of the Effects of Cash Transfer Programs on Schooling Outcomes." Journal of Development Effectiveness 6(1):1-43.

Baird, Sarah, and Berk Özler. 2012. "Examining the Reliability of Self-Reported Data on School Participation." Journal of Development Economics 98(1):89-93.

Baland, Jean-Marie, and James A. Robinson. 2001. "Is Child Labor Inefficient?" Journal of Political Economy 108(4):663-79.

Banerjee, Abhijit, Dean Karlan, and Jonathan Zinman. 2015. "Six Randomized Evaluations of Microcredit: Introduction and Further Steps." American Economic Journal: Applied Economics 7(1):1-21.

Barber, Sarah L., and Paul J. Gertler. 2008. "The Impact of Mexico's Conditional Cash Transfer Programme, Oportunidades, on Birthweight." Tropical Medicine and International Health 13(11):1405-14.

Barrera-Osorio, Felipe, Marianne Bertrand, Leigh L. Linden, and Francisco Perez-Calle. 2011. "Improving the Design of Conditional Transfer Programs: Evidence from a Randomized Education Experiment in Colombia." American Economic Journal: Applied Economics 3(2):167-95.

Basu, Kaushik, and Pham Hoang Van. 1998. "The Economics of Child Labor.” American Economic Review 88(3):412-27.

Beegle, Kathleen, Rajeev Dehejia, and Roberta Gatti. 2006. "Child Labor and Agricultural Shocks." Journal of Development Economics 81(1):80-96.

Benhassine, Najy, Florencia Devoto, Esther Duflo, Pascaline Dupas, and Victor Pouliquen. 2015. "Turning a Shove into a Nudge? A 'Labeled Cash Transfer' for Education." American Economic Journal: Economic Policy 7(3):86-125.

Bleakley, Hoyt. 2007. "Disease and Development: Evidence from Hookworm Eradication in the American South.” Quarterly Journal of Economics 122(1):73-117.

Bobba, Matteo, and Jeremie Gignoux. 2014. "Policy Evaluation in the Presence of Spatial Externalities: Reassessing the Progresa Program.” PSE Working Paper 2011-37. Paris School of Economics.

Bobonis, Gustavo J., and Frederico Finan. 2009. "Neighborhood Peer Effects in Secondary School Enrollment Decisions." Review of Economics and Statistics 91(4):695-716. 
Bourguignon, Francois, F.H. Ferreira, and Philippe G. Leite. 2003. "Conditional Cash Transfers, Schooling, and Child Labor: Micro-Simulating Brazil's Bolsa Escola Program." The World Bank Economic Review 17(2):229-54.

Contreras, Diana, and Pushkar Maitra. 2013. "Health Spillover Effects of a Conditional Cash Transfer Program.” No. 44-13. Melbourne, Australia: Monash University, Department of Economics.

Das, Jishnu, Quy-Toan Do, and Berk Özler. 2005. "Reassessing Conditional Cash Transfer Programs.” World Bank Research Observer 20(1):57-80.

de Hoop, Jacobus, and Furio. C. Rosati. 2014. "Cash Transfers and Child Labor." World Bank Research Observer 29(2):202-34.

Department of Social Welfare and Development. 2015. Pantawid Pamilya Financials. http:// pantawid.dswd.gov.ph/index.php/pantawid-pamilya-financials (accessed May 4, 2016).

Edmonds, Eric. V. 2008. "Child Labor.” In Handbook of Development Economics. Volume 4, ed. T. Schultz and J. Strauss, 3607-709. New York: Elsevier.

Edmonds, Eric. V., and Norbert Schady. 2012. "Poverty Alleviation and Child Labor." American Economic Journal: Economic Policy 4(4):100-24.

Ferreira, Francisco H.G., Deon Filmer, and Norbert Schady. 2009. "Own and Sibling Effects of Conditional Cash Transfer Programs.” World Bank Policy Research Working Paper 5001. Washington, DC: World Bank.

Fiszbein, Ariel, and Norbert Schady. 2009. Conditional Cash Transfers: Reducing Present and Future Poverty. Washington, DC: World Bank.

Freedman, David A. 2008a. "On Regression Adjustments to Experimental Data." Advances in Applied Mathematics 40:180-93.

. 2008b. "On Regression Adjustments in Experiments with Several Treatments." The Annals of Applied Statistics 2:176-96.

Gertler, Paul. 2004. "Do Conditional Cash Transfers Improve Child Health? Evidence from PROGRESA's Control Randomized Experiment.” American Economic Review 94(2):336-41. Gertler, Paul, Sebastian W. Martinez, Marta Rubio-Codina. 2012. "Investing Cash Transfers to Raise Long-Term Living Standards." American Economic Journal: Applied Economics 4(1):164-92.

Jacoby, Hanan, and Emmanuel Skoufias. 1997. "Risk, Financial Markets, and Human Capital in a Developing Country." Review of Economic Studies 64:311-35.

Kandpal, Eeshani, Harold Alderman, Jed Friedman, Deon Filmer, Junko Onishi, and Jorge Avalos. 2016. "A Conditional Cash Transfer Program in the Philippines Reduces Severe Stunting." The Journal of Nutrition 146(9):1793-1800.

Lalive, Rafael, and M. Alejandra Cattaneo. 2009. "Social Interactions and Schooling Decisions." The Review of Economics and Statistics 91(3):457-77.

Lin, Winston. 2013. "Agnostic notes on Regression Adjustments to Experimental Data:

Reexamining Freedman's Critique.” The Annals of Applied Statistics 7(1):295-318.

Manacorda, Marco. 2006. "Child Labor and the Labor Supply of Other Household Members: Evidence from 1920 America." American Economic Review 96(5):1788-1801.

Miguel, Edward, and Michael Kremer. 2004. "Worms: Identifying Impacts on Education and Health in the Presence of Treatment Externalities." Econometrica 72(1):159-217.

Nelson, Leah K. 2011. "From Loans to Labor: Access to Credit, Entrepreneurship, and Child Labor." Unpublished. http://www.colorado.edu/Economics/seminars/SeminarArchive/2011-12 /Nelson.pdf (accessed July 17, 2018).

Ozer, Emily J., Lia C.H. Fernald, Ann Weber, Emily P. Flynn, and Tyler J. VanderWeele. 2011. "Does Alleviating Poverty Affect Mothers' Depressive Symptoms? A Quasi-Experimental Investigation of Mexico's Oportunidades Programme." International Journal of Epidemiology 40(6):1565-76. 
Parker, Susan. W., Luis Rubalcava, and Graciela Teruel. 2008. "Evaluating Conditional Schooling and Health Programs." In Handbook of Development Economics, Volume 4, ed. T. Schultz and J. Strauss, 3963-4035. New York: Elsevier.

Ravallion, Martin, and Quentin Wodon. 2000. "Does Child Labor Displace Schooling? Evidence on Behavioral Responses to an Enrollment Subsidy." The Economic Journal 110(462): C158-75.

Rivera, Juan A., Daniela Sotres-Álvarez, Jean-Pierre Habicht, Teresa Shamah, and Salvador Villalpando. 2004. "Impact of the Mexican Program for Education, Health, and Nutrition (PROGRESA) on Rates of Growth and Anemia in Infants and Young Children: A Randomized Effectiveness Study." JAMA 291(21):2563-70.

Rubio-Codina, Marta. 2010. "Intra-Household Time Allocation in Rural Mexico: Evidence from a Randomized Experiment." In Child Labor and the Transition between School and Work, Research in Labor Economics 31, ed. Randall K.Q. Akee, Eric V. Edmonds, and Konstantinos Tatsiramos, 219-57. Bingley, UK: Emerald Group Publishing Limited.

Saavedra, Juan E., and Sandra Garcia. 2012. "Impacts of Conditional Cash Transfers on Educational Outcomes in Developing Countries: A Meta-Analysis." Rand Working Paper 921-1. Santa Monica, CA: RAND.

Schady, Norbert, Maria Caridad Araujo, Ximena Peña, and Luis F. López-Calva. 2008. "Cash Transfers, Conditions, and School Enrolment in Ecuador." Economía 8(2):43-77.

Schultz, T. Paul. 2004. "School Subsidies for the Poor: Evaluating the Mexican Progresa Poverty Program." Journal of Development Economics 74(1):199-250.

Skoufias, Emmanuel, and Susan W. Parker. 2001. "Conditional Cash Transfers and Their Impact on Child Work and Schooling: Evidence from the PROGRESA Program in Mexico." Economía 2(1):45-96.

Understanding Children's Work. 2015. "Understanding Children's Work and Youth Employment Outcomes in the Philippines."

U.S. Department of Labor. 2016. "Philippines: 2015 Findings on the Worst Forms of Labor: Significant Advancement.” Washington, DC: U.S. Department of Labor.

World Bank. 2013. "Philippines Conditional Cash Transfer Program Impact Evaluation 2012." World Bank Report 75533-PH. Washington, DC: World Bank. https://openknowledge .worldbank.org/handle/10986/13244 (accessed July 25, 2018). 